\title{
Spillover Reoxidation of Ceria Nanoparticles
}

David C. Grinter ${ }^{\dagger}$, Chris Muryn ${ }^{\mathbb{I}}$, Alessandro Sala ${ }^{\S}$, Chi-Ming Yim ${ }^{\dagger}$, Chi L. Pang ${ }^{\dagger}$, Tevfik O. Menteş ${ }^{\S}$, Andrea Locatelli ${ }^{\S}$ and Geoff Thornton ${ }^{\dagger}, *$

'Department of Chemistry and London Centre for Nanotechnology, University College London, London, WC1H 0AJ, UK

"Chemistry Department, Brookhaven National Laboratory, Upton, NY, 11973, USA

"School of Chemistry and Photon Science Institute, University of Manchester, Manchester, M13 9PL, UK

${ }^{\S}$ Elettra - Sincrotrone Trieste S.C.p.A., Basovizza, Trieste, 34149, Italy

*CORRESPONDING AUTHOR:

Professor Geoff Thornton

Department of Chemistry, University College London

20 Gordon Street, London WC1H 0AJ, UK

tel: +44 (0)20 7679 7979, fax: +44 (0)20 7679 0595, email: g.thornton@ucl.ac.uk 


\begin{abstract}
Interest in resolving the mechanisms behind ceria's activity has been intense due to the numerous industrial applications including those in heterogeneous catalysis. In this work we study the reduction and reoxidation of ultrathin $\mathrm{CeO}_{2}(111)$ nano-islands on $\mathrm{Rh}(111)$ and $\mathrm{Pt}(111)$ substrates, so-called inverse model catalysts, with a combination of real and reciprocal space techniques based on x-ray photoemission electron microscopy (XPEEM) and low energy electron microscopy (LEEM). Soft x-ray micro-focused illumination was employed to reduce the ceria islands, which we are able to control by varying the oxygen partial pressure within the measurement chamber. Low energy electron diffraction measurements of the irradiated ceria films demonstrate the formation of an ordered array of oxygen vacancies leading to a $(\sqrt{ } 7 \times \sqrt{ } 7) \mathrm{R} 19.1^{\circ}$ superstructure attributed to the $\mathrm{t}^{-}$ phase $\left(\mathrm{Ce}_{7} \mathrm{O}_{12}\right)(111)$. Resonant photoelectron spectroscopy provides the required high sensitivity to detect small changes in $\mathrm{Ce}^{3+}$ concentration. The high spatial resolution of the XPEEM allows us to determine that the reduction of the ceria occurs initially at the interface of the islands with the Rh support. Reoxidation of the $\mathrm{CeO}_{2-\mathrm{x}}(111)$ to $\mathrm{CeO}_{2}(111)$ proceeds via spillover of activated oxygen adsorbed on the $\mathrm{Rh}(111)$ surface as a $(2 \times 2)$ overlayer. Our results highlight the important role that the noble metal plays in the re-generation of the stoichiometric ceria surface, a vital step in many reactions on ceria. This differs from the commonly-proposed Mars-van-Krevelen model in which reoxidation involves direct reaction of the ceria with $\mathrm{O}_{2}$.
\end{abstract}


Stimulated by their applications in varied fields, including heterogeneous catalysis, ${ }^{1}$ electronic devices, ${ }^{1,2}$ chemical sensing, ${ }^{3}$ and fuel cells, ${ }^{4}$ ceria-based $\left(\mathrm{CeO}_{2}\right)$ materials have been the focus of intensive study for a number of years. As a reducible oxide with facile oxygen vacancy formation and conversion between the $\mathrm{Ce}^{3+}$ and $\mathrm{Ce}^{4+}$ oxidation states, ceria has excellent oxygen storage capacity and therefore displays good characteristics as a catalyst support. ${ }^{1,5}$ Ceria is often employed as a support for nanoparticles of metals such as $\mathrm{Au}, \mathrm{Pt}, \mathrm{Rh}$ and $\mathrm{Pd}$, where it can stabilise the dispersion of such metals resulting in increased activity. Production of hydrogen for use in fuel cells requires removal of $\mathrm{CO}$ contaminants, normally via a combination of water-gas-shift (WGS) and preferential oxidation (PROX). ${ }^{4}$ Ceria based catalysts show promise for both of these processes: $\mathrm{Au} /$ ceria displays high activity for the low temperature WGS reaction, ${ }^{6}$ and $\mathrm{Rh} /$ ceria for PROX.7 ${ }^{7}$ Of key importance in such ceria-supported metal systems under catalytic conditions is spillover of oxygen and other species from the oxide support onto the metal and vice-versa, depending on the reaction conditions. ${ }^{8-10}$ The importance of ultrathin epitaxial $\mathrm{CeO}_{2}(111)$ islands with lateral dimensions up to a few hundred nm, supported on a metal surface - a so-called inverse model catalyst - is well recognized with common substrates including $\mathrm{Au}(111),{ }^{11} \mathrm{Ru}(0001),{ }^{12} \mathrm{Cu}(111),{ }^{13}$ $\operatorname{Pt}(111),{ }^{14}$ and $\operatorname{Rh}(111) .{ }^{15,16}$ The activation of oxygen species on ceria-supported noble metal particles has been demonstrated by isotope exchange experiments, ${ }^{10}$ however on inverse catalysts there is a paucity of reactivity data. The large area of metal substrate (e.g $\mathrm{Rh}, \mathrm{Ru}$ ) relative to the ceria islands may play an important role in the activity and reaction mechanisms of such systems. Inverse catalysts permit the investigation of novel effects at the interfaces between the ceria and the metal substrates as well as mitigating the charging effects observed when electron based techniques are used to probe insulating oxides. Low energy electron microscopy (LEEM) and x-ray photoemission electron microscopy (XPEEM) have previously been used to probe ceria films on substrates including $\mathrm{Pt}(111),{ }^{17} \mathrm{Re}(0001),{ }^{18} \mathrm{Ru}(0001),{ }^{19-21} \mathrm{~W}(110),{ }^{22}$ and $\mathrm{Cu}(111) .{ }^{23}$ These techniques combine high-quality spectroscopy with excellent lateral resolution and provide useful insights into the structure and chemistry of such films. 
In this work we are particularly interested in the reoxidation step in the catalytic cycle involving ceria. To explore this process requires the initial reduction of ultrathin (111) oriented ceria films grown on $\mathrm{Rh}(111)$ and $\mathrm{Pt}(111)$, for which we employ the micro-focussed soft-X-ray beam from a $3^{\text {rd }}$ generation synchrotron source. This avoids complications arising from chemical-reaction induced reduction, such as modification of the metal support in the inverse catalyst. The reduction of oxides, including ceria, by an X-ray beam has been extensively reported. ${ }^{24-37}$ The likely mechanism involves core level excitation followed by interatomic Auger decay leading to a multiple ionisation of the oxygen atom, which is readily released from the solid. ${ }^{38} \mathrm{We}$ demonstrate that reoxidation of the reduced ultrathin film involves oxygen provided from the metal support, which leads to important insights into the behaviour of the catalyst system.

\section{RESULTS AND DISCUSSION}
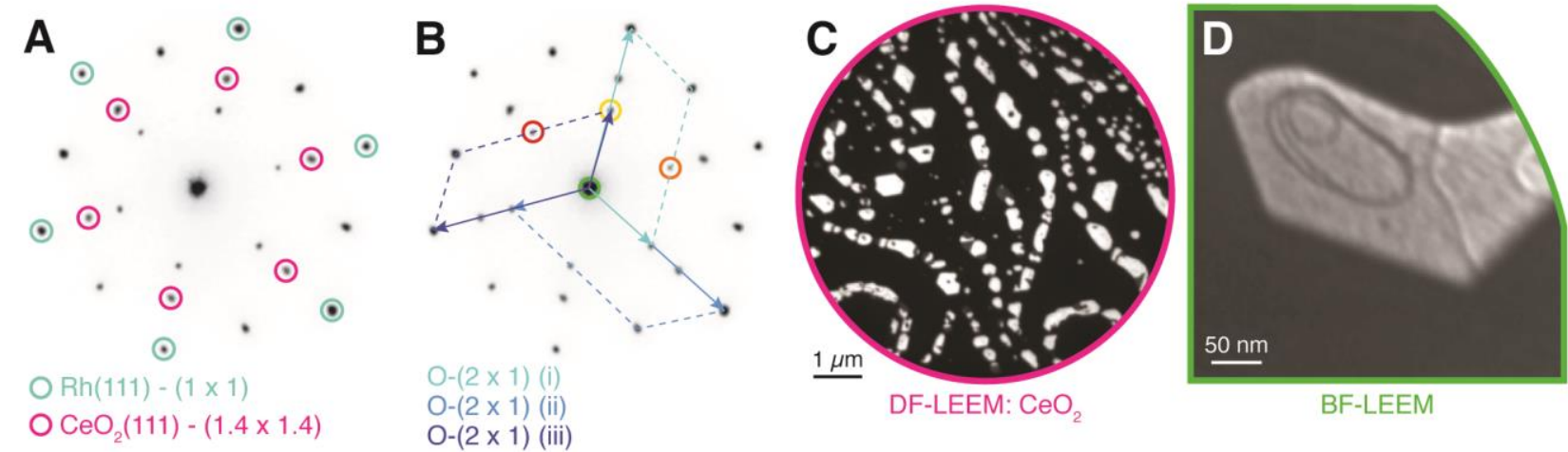

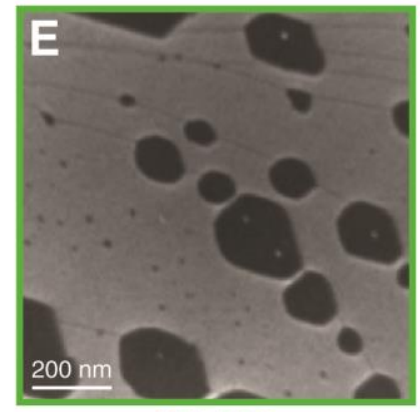

BF-LEEM

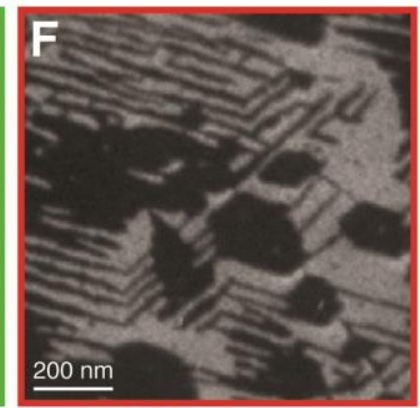

DF-LEEM: O-(2 x 1)

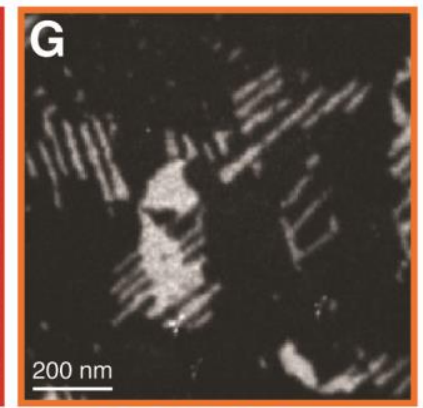

DF-LEEM: O- $(2 \times 1)$

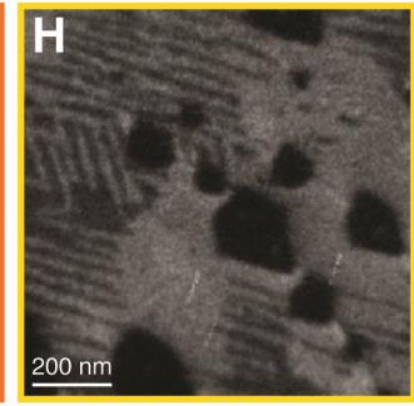

DF-LEEM: $0-(2 \times 1)$

Figure 1.The structure of the model $\mathrm{CeO}_{2}(111) / \mathrm{Rh}(111)$ catalyst system. (A) LEED: the spots corresponding to the substrate and the ceria are highlighted in blue and pink, respectively $(\mathrm{S} . \mathrm{V} .=35 \mathrm{~V})$. (B) The same LEED pattern with the three domains of the Rh(111)-O- $(2 \times 1)$ overlayer highlighted (S.V. $=35 \mathrm{~V})$. (C) Darkfield (DF) LEEM using the $\mathrm{CeO}_{2}$ diffraction beams; bright ceria islands are clearly visible $(\mathrm{S} . \mathrm{V} .=30 \mathrm{~V})$. (D) High-resolution LEEM image of a ceria island $($ S.V. $=10 \mathrm{~V}) .(\mathbf{E})$ Bright field LEEM image where the ceria 
islands appear as dark patches on a bright background. (S.V. $=30 \mathrm{~V}$,). (F-H) DF-LEEM from the O- $(2 \times 1)$ overlayer (colors correspond to the LEED spots highlighted in (B)), the ceria islands appear as dark patches in all three images. $(\mathrm{S} . \mathrm{V} .=35 \mathrm{~V})$.

The inverse model catalysts prepared in this work are composed of micron-sized ceria islands separated by extended regions of oxygen-covered metal substrate, similar to our earlier work ${ }^{16-18}$ and other LEEM investigations. ${ }^{19-21}$ A typical LEED pattern $(35 \mathrm{~V})$ of a $0.5 \mathrm{MLE} \mathrm{CeO}_{2}(111)$ film on $\mathrm{Rh}(111)$ is displayed in Figure 1A and 1B. The sharp, well-ordered pattern shows the first order $\mathrm{Rh}(111)-(1 \times 1)$, the first order $\mathrm{CeO}_{2}(111)$ at a spacing of $(1.4 \times 1.4)$ relative to the substrate, and an oxygen overlayer which has a $(2 \times 1)$ periodicity. The three $(2 \times 1)$ domains are rotated by $120^{\circ}$ with respect to each other, as depicted in Figure 1B and shown in an earlier STM study of the O-Rh(111) system. ${ }^{39}$ A dark-field (DF) LEEM image, acquired using one of the first order $\mathrm{CeO}_{2}$ diffraction beams, is shown in Figure 1C. The bright ceria islands can clearly be identified, with a variety of truncated hexagonal shapes and lateral dimensions ranging from 50 to $500 \mathrm{~nm}$. A number of the islands exhibit depressions in their centers. A high resolution LEEM image of a thicker $\mathrm{CeO}_{2}$ island is shown in Figure 1D where atomic step edges in the centre of the island are observed, along with what appears to be a line dislocation running through it. The origin of the oval step edges visible in Figure $1 \mathrm{D}$ is not entirely clear but at the low electron energy used $(10 \mathrm{eV})$ it is likely that we are looking "through" the ceria and observing contrast from steps in the substrate underneath, over which carpet-like growth of the ceria has occurred. A bright-field (BF) LEEM image (formed using the specularly reflected electrons) of the film is displayed in Figure 1E. At the particular electron energy used, the $\mathrm{Rh}(111)$ substrate appears bright, and the ceria islands form dark shadows. As well as the large islands, we can also see some very small spots probably originating from ceria that had not yet coalesced into a larger island. The step edges of the $\mathrm{Rh}(111)$ substrate can also be seen and it is clear that these act as nucleation sites for the island growth. To investigate the nature of the oxygen overlayer on the uncovered substrate in more detail, DF-LEEM images (Figure 1F-H) were acquired from three of the half-order spots in the LEED as highlighted in red, orange and yellow in Figure $1 \mathrm{~B}$. From the images in Figure $1 \mathrm{~F}$ and $1 \mathrm{G}$ the rotated domains of $\mathrm{O}-(2 \times 1)$ are clear, and 
Figure $1 \mathrm{H}$ can be seen to be effectively the sum of $1 \mathrm{~F}$ and $1 \mathrm{G}$. This is consistent with the LEED pattern, which shows that the spot highlighted in yellow has contributions from two of the rotated $(2 \times 1)$ domains.

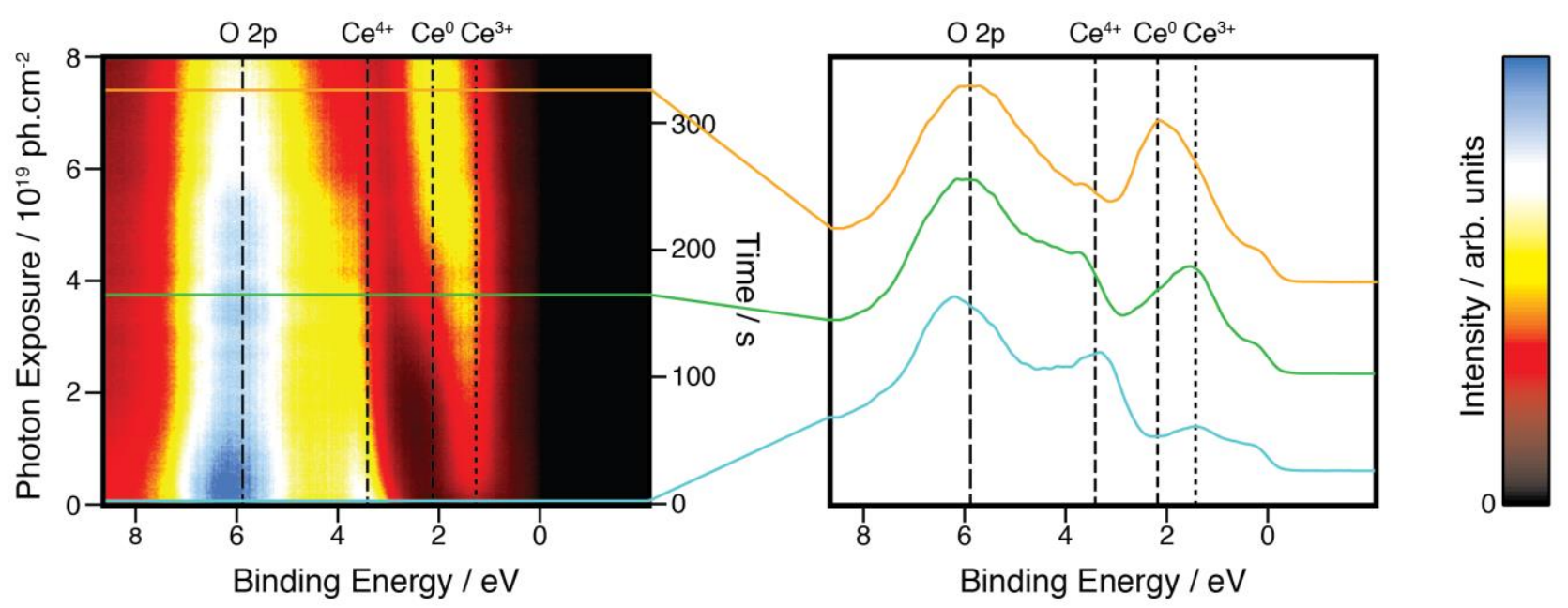

Figure 2. Resonant $\mu$-XPS spectra $\left(\mathrm{h} v=120.8 \mathrm{eV}\right.$, on-resonance for $\left.\mathrm{Ce}^{3+}\right)$ of the valence band $(\mathrm{VB})$ fora 0.5 MLE $\mathrm{CeO}_{2}(111)$ film on $\mathrm{Rh}(111)$ as a function of photon exposure under UHV conditions.

Resonant XPS of the Ce 4f levels in the valence band has been shown to be a powerful tool for probing changes in the oxidation state of the cerium, with very high surface sensitivity. ${ }^{40}$ Figure 2 shows a plot of successive VB spectra for our model system (acquired in the $\mu$-XPS mode of the XPEEM microscope, probing an area of $\sim 2 \mu \mathrm{m}$ diameter) at a photon energy of $120.8 \mathrm{eV}$ (onresonance for $\mathrm{Ce}^{3+}$ ) versus photon exposure (left axis) and exposure time (right axis). Selected spectra are shown in the panel on the right hand side. At the start of the experiment (blue spectrum in Figure 2), the VB region is characterised by an intense $\mathrm{O} 2 \mathrm{p}$ feature ( $6 \mathrm{eV}$ B.E.) due to oxygen in the ceria and on the $\mathrm{Rh}$ substrate, as well as a clear $\mathrm{Ce} 4 \mathrm{f}(4+)$ component $(\sim 3.5 \mathrm{eV}$ B.E. $)$ and only a minor $\mathrm{Ce} 4 \mathrm{f}(3+)$ component ( 1.5 eV B.E.). The Ce $4 \mathrm{f}$ orbital is formally unoccupied when ceria is stoichiometric $\mathrm{CeO}_{2}$, however hybridization with the $\mathrm{O} 2 \mathrm{p}$ leads to a feature which is attributed to $\mathrm{Ce}^{4+}$ species. $^{41}$ Upon illumination with the intense SR soft $\mathrm{x}$-rays, there is rapid reduction of the ceria, as demonstrated by the decrease of the $\mathrm{Ce}^{4+}$ intensity and concomitant increase of the $\mathrm{Ce}^{3+}$ intensity (green spectrum in Figure 2). Indeed this reduction is so efficient that after $\sim 5$ minutes under the beam (orange spectrum in Figure 2) the $\mathrm{Ce}^{4+}$ component is negligible, 
and in addition to the large $\mathrm{Ce}^{3+}$ feature we observe a component at $\sim 2.2 \mathrm{eV}$ B.E. which was attributed by Škoda et al. to metallic $\mathrm{Ce}^{0 .} .^{41}$ As well as the obvious spectroscopic changes, the illumination has visible effects in LEEM imaging, as shown in Figure S2 of the supporting information. A change in contrast of the ceria islands is visible where the sample has been exposed to the x-ray beam. The extremely efficient reduction of the ceria under the beam is likely due to the large X-ray absorption cross-section at the $\mathrm{Ce} \mathrm{N}_{6,7}$ edge at a photon energy of $120.8 \mathrm{eV},{ }^{42}$ assuming a Knotek-Feibelman type mechanism for the stimulated desorption of oxygen.

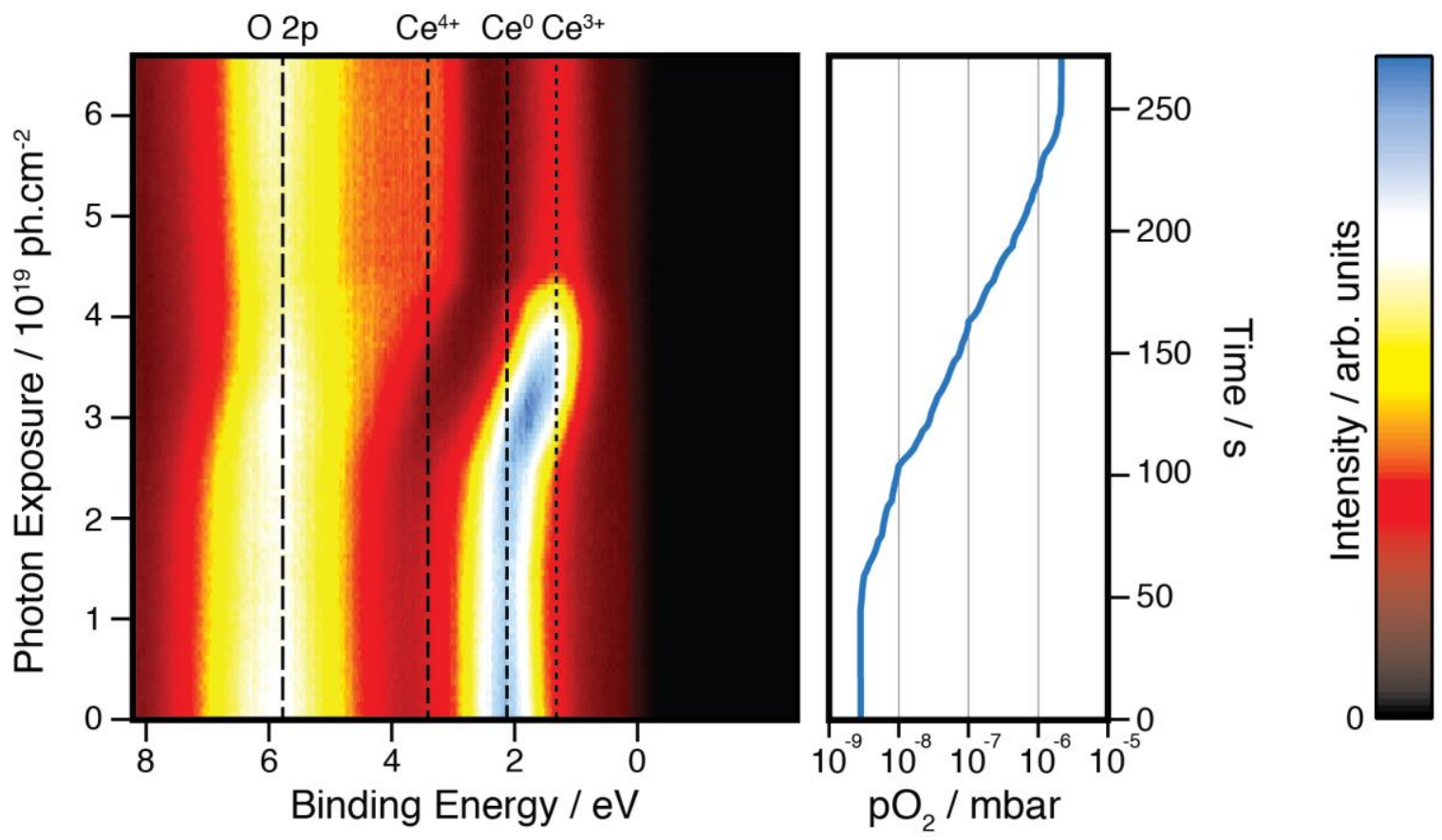

Figure 3. Resonant valence band XPS spectra of $\mathrm{CeO}_{\mathrm{x}}(111) / \mathrm{Rh}(111)$ under illumination with soft $\mathrm{X}$-rays (hv $=120.8 \mathrm{eV}$ ) as the $\mathrm{pO}_{2}$ within the chamber is increased from $3 \times 10^{-9}$ mbar to $2 \times 10^{-6}$ mbar, leading to near complete reoxidation of the ceria at $300 \mathrm{~K}$.

In order to probe the reversibility of the process, that is to say the reoxidation of the X-ray reduced film, resonant VB XPS was carried out on a previously exposed area of the sample as the $\mathrm{O}_{2}$ pressure was ramped slowly from $3 \times 10^{-9}$ mbar to $2 \times 10^{-6}$ mbar. The resultant spectra are displayed in Figure 3 against time/photon exposure and the corresponding $\mathrm{pO}_{2}$. At the start of the process, in $\mathrm{UHV}$, the valence band of the highly-reduced surface is dominated by the $\mathrm{Ce}^{0}$ component at $\sim 2.2$ $\mathrm{eV}$ B.E. and the $\mathrm{O} 2 \mathrm{p}$ at $\sim 6 \mathrm{eV}$. At $\sim 2 \times 10^{-8} \mathrm{mbar}_{2}$ there is a clear and immediate reversal of the $\mathrm{X}$-ray induced reduction as the $\mathrm{Ce}^{0}$ component decreases and the $\mathrm{Ce}^{3+}$ component dominates. As 
the $\mathrm{pO}_{2}$ is increased further, the $\mathrm{Ce}^{3+}$ decreases almost to zero and the $\mathrm{Ce}^{4+}$ increases, indicating the near complete reoxidation of the ceria in $2 \times 10^{-6} \mathrm{mbar}_{2}$ at $300 \mathrm{~K}$. In order to completely reoxidize the ceria, it would be expected that some heating is required, even in the presence of a relative high $\mathrm{pO}_{2}$. Indeed, Figure S3 demonstrates the evolution of the VB XPS while heating the previously damaged area in $2 \times 10^{-6}$ mbar $\mathrm{O}_{2}$ from $\sim 300 \mathrm{~K}$ to $460 \mathrm{~K}$. Above $\sim 420 \mathrm{~K}$, there is no further reoxidation possible (the $\mathrm{Ce}^{3+}$ component reaches a minimum). Although a very slight feature persists, this is likely due to the $\mathrm{Rh} 4 \mathrm{~d}$ peak also present in that region of the $\mathrm{VB}$. The complementary experiment to this (where the oxygen pressure is slowly decreased from $2 \times 10^{-6}$ mbar to $5 \times 10^{-9}$ mbar) shows exactly the reverse of Figure 3, with the same major transition at $\sim 2 \times 10^{-8}$ mbar, and is displayed in Figure S4.

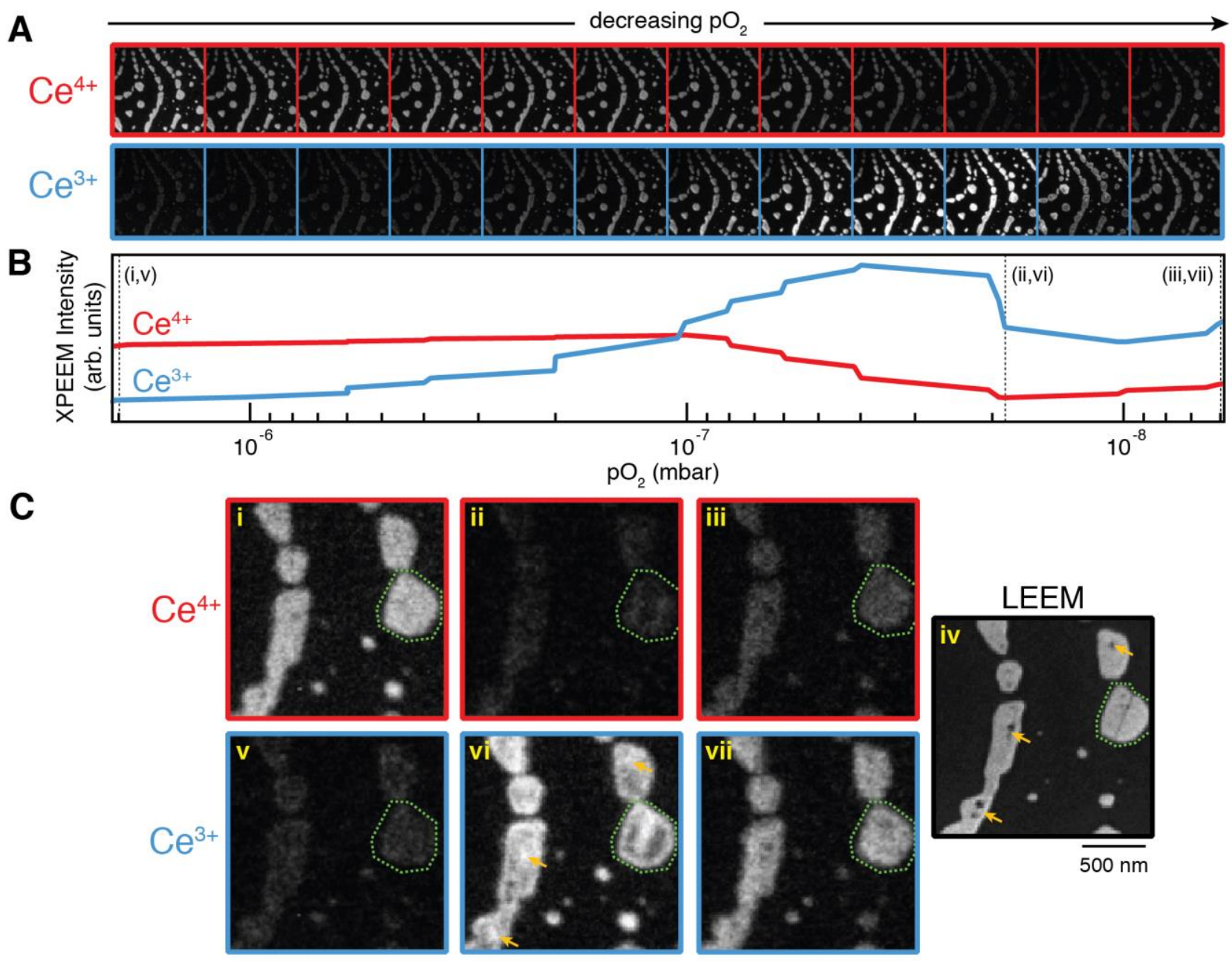

Figure 4. Energy-filtered XPEEM images tracking the reduction of individual ceria islands on $\mathrm{Rh}(111)$ under $\mathrm{x}$-ray illumination. The images were all obtained with a photon energy of $121 \mathrm{eV}$ (on-resonance for $\left(\mathrm{Ce}^{3+}\right)$ and two kinetic energies were selected: Red corresponding to a B.E. $=3.5 \mathrm{eV}\left(\mathrm{Ce}^{4+}\right)$ and Blue corresponding to a B.E. $=1.5 \mathrm{eV}\left(\mathrm{Ce}^{3+}\right)(\mathrm{A}) \mathrm{XPEEM}$ images (Field of view, FOV $=4 \mu \mathrm{m}$ ) obtained as the oxygen partial pressure was decreased in a stepwise manner from $2 \times 10^{-6} \mathrm{mbar}$ to $6 \times 10^{-9} \mathrm{mbar}$. (B) A plot of 
the average intensity of the ceria islands in the XPEEM images in (A) vs. $\mathrm{O}_{2}$ partial pressure. (C) High resolution energy-filtered XPEEM images obtained as $\mathrm{pO}_{2}$ is reduced from $2 \times 10^{-6}$ mbar to $6 \times 10^{-9}$ mbar: (iiii) $\mathrm{Ce}^{4+},\left(\mathrm{v}\right.$-vii) $\mathrm{Ce}^{3+}$, (iv) DF-LEEM image (ceria first order beam) obtained prior to reduction. (S.V. = 30 V)

In order to examine microscopically the photon-induced reduction of the ceria islands in situ at 300 $\mathrm{K}$, the energy-filtered XPEEM mode was employed to obtain images sequentially at two kinetic energies corresponding to the $\mathrm{Ce}^{3+}$ and $\mathrm{Ce}^{4+}$ contributions to the $\mathrm{Ce} 4 \mathrm{f}$ level in the valence band (B.E. $=1.5 \mathrm{eV}$ and $3.5 \mathrm{eV}$, respectively) as the $\mathrm{pO}_{2}$ in the chamber was slowly decreased. Selected large scale $(\mathrm{FOV}=4 \mu \mathrm{m})$ XPEEM images are shown in Figure 4A (red: $\mathrm{Ce}^{4+}$, blue: $\left.\mathrm{Ce}^{3+}\right)$ along with a plot of the intensity of the islands versus $\mathrm{pO}_{2}$ in Figure $4 \mathrm{~B}$. At the beginning of the sequence $\left(\mathrm{pO}_{2}=2 \times 10^{-6}\right.$ mbar), the ceria islands are almost stoichiometric $\mathrm{CeO}_{2}$, and entirely composed of $\mathrm{Ce}^{4+}$ species with very little intensity due to $\mathrm{Ce}^{3+}$. As the oxygen pressure is reduced, the intensity of the $\mathrm{Ce}^{4+}$ component decreases, and the intensity from $\mathrm{Ce}^{3+}$ species increases uniformly. At a $\mathrm{pO}_{2}$ of $\sim 2 \times 10^{-8}$ mbar, there is a sharp drop in intensity from $\mathrm{Ce}^{3+}$ which can be attributed to the formation of $\mathrm{Ce}^{0}$ species, which have a slightly higher $\mathrm{Ce} 4 \mathrm{f}$ binding energy, as the top layers of the ceria islands become very oxygen deficient. $\mathrm{As}_{\mathrm{pO}}$ is decreased further there are only minor changes to the $\mathrm{Ce}^{3+}$ intensity and there is a slight increase in intensity at $3.5 \mathrm{eV}$ binding energy, due to the development of the $\mathrm{Ce}^{0}$ peak as well as other changes to the $\mathrm{O} 2 \mathrm{p}$ region as observed in Figure 2. Figure 4C shows magnified regions of the XPEEM images $(\mathrm{FOV}=1.8 \mu \mathrm{m})$ obtained at oxygen pressures of $2 \times 10^{-6}$ mbar (i,v), $2 \times 10^{-8}$ mbar (ii, vi), and $6 \times 10^{-9} \mathrm{mbar}$ (iii, vii) obtained at energies corresponding to $\mathrm{Ce}^{4+}$ (red) and $\mathrm{Ce}^{3+}$ (blue). Figure $4 \mathrm{C}(\mathrm{iv})$ is a high-resolution dark-field LEEM image of the same area that shows the morphology of the ceria islands in more detail. At the start of the reduction process there is uniform contrast for both $\mathrm{Ce}^{3+}$ and $\mathrm{Ce}^{4+}$ across the surface of the islands. In the partially reduced state (Figure 4Cvi) there is clearly a non-uniform distribution of $\mathrm{Ce}^{3+}$ species across the islands. The perimeters of the islands and holes/domain boundaries within them (marked in yellow) remain brighter, indicating a higher $\mathrm{Ce}^{3+}$ concentration. In the corresponding map of $\mathrm{Ce}^{4+}$ (Figure 4Cii) the opposite effect is observed, the regions around the edges and defects appear darker than the central parts of the islands. Upon further reduction (Figure 
4Ciii, vii), again a uniform distribution of both $\mathrm{Ce}^{3+}$ and $\mathrm{Ce}^{4+}$ is observed, with inverted intensities compared to the oxidized surface.

The interface between the ceria and the support in an inverse model catalyst has been proposed as the reactive site for the water-gas-shift reaction over ceria/Au(111) ${ }^{11}$. Our observations of increased reducibility under photon irradiation at the island edges of our ceria/ $\operatorname{Rh}(111)$ system further highlights the importance of studying such interfaces. The origin of this enhanced reducibility at the island edges is not clear, however the interface with the $\mathrm{Rh}$ may lead to destabilization of $\mathrm{Ce}^{4+}$ perhaps via facile oxygen exchange with the substrate, leading to the observed preferential reduction.

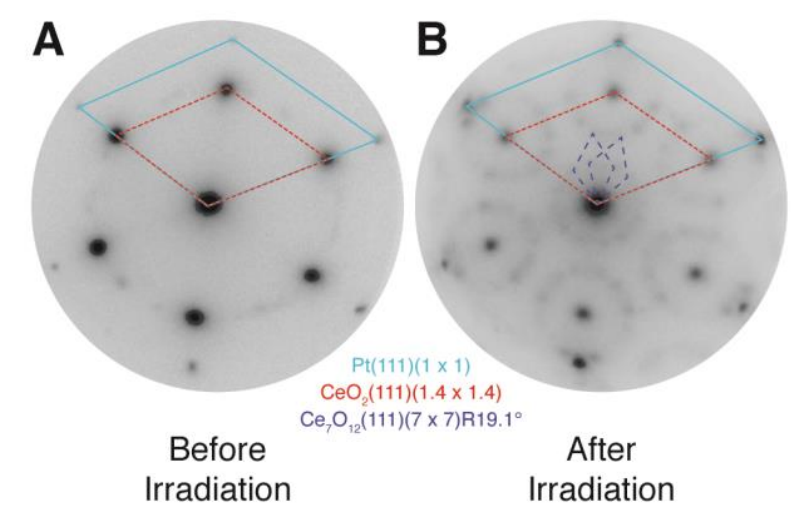

Figure 5. LEED patterns $(\mathrm{S} . \mathrm{V} .=40 \mathrm{~V})$ demonstrating the effects of soft $\mathrm{x}$-rayirradiation of a 10 MLE $\mathrm{CeO}_{2}$ (111) film on $\mathrm{Pt}(111)$. (A) LEED pattern of the as-prepared film showing faint $\operatorname{Pt}(111)-(1 \times 1)$ reflexes (blue solid highlight) and intense $\mathrm{CeO}_{2}(111)-(1.4 \times 1.4)$ (red dotted highlight), with some rotated ceria reflexes also visible. (B) LEED pattern after irradiation with $1.5 \times 10^{21} \mathrm{ph}_{\mathrm{cm}} \mathrm{cm}^{-2}(\mathrm{~h} v=120.8 \mathrm{eV})$. The additional spots form a $(\sqrt{ } 7 \times \sqrt{ } 7) \mathrm{R} 19.1^{\circ}$ superstructure with respect to the $\mathrm{CeO}_{2}(111)$ with a mirror domain (purple dashed highlight).

The effects of photon-induced reduction of the ceria can also be observed in the LEED patterns of the films; to illustrate this we have prepared thick ceria films on a $\operatorname{Pt}(111)$ substrate. Figure 5A presents a LEED pattern acquired immediately after the preparation of a $10 \mathrm{MLE} \mathrm{CeO}_{2}(111)$ film on $\operatorname{Pt}(111)$ which has a very similar structure to those formed on $\mathrm{Rh}(111)$. Due to the high ceria coverage, the $\operatorname{Pt}(111)-(1 \times 1)$ reflexes (blue solid line) are relatively faint in comparison with the $\mathrm{CeO}_{2}(111)-(1.4 \times 1.4)$ (red dotted line). Also present are a number of rotated phases of the ceria, a feature previously observed for films prepared on $\operatorname{Re}(0001)^{18}$ and $\operatorname{Ru}(0001)^{20}$. After exposing the 
film to the x-ray beam for 30 minutes (a total exposure of $1.5 \times 10^{21} \mathrm{ph} . \mathrm{cm}^{-2}$ ) at a photon energy of $120.8 \mathrm{eV}$ (as used for resonant XPS measurements) the LEED pattern (Figure 5B) showed the presence of a weak $(\sqrt{7} \times \sqrt{7}) \mathrm{R} 19.1^{\circ}$ superstructure with respect to the ceria (purple dashed line) with a mirror domain, along with a decrease in the intensity of the first-order $\mathrm{CeO}_{2}(111)$ spots. This superstructure can be attributed to the formation of a partial layer of the 1-phase $\left(\mathrm{Ce}_{7} \mathrm{O}_{12}\right)(111)$ across some of the surface of the $\mathrm{CeO}_{2}(111)$ islands, which consists of an ordered arrangement of oxygen vacancies. ${ }^{43}$ This reduction via photon stimulated desorption contrasts with that observed for ceria reduction under $\mathrm{H}_{2}$ at $700 \mathrm{~K}$, where $(3 \times 3)$ and $(4 \times 4)$ reconstructions were observed during the course of the reduction process, but not a $(\sqrt{ } 7 \times \sqrt{ } 7) \mathrm{R} 19.1^{\circ} .{ }^{44}$ Arrays of ordered oxygen vacancies have been observed on the surface of $\mathrm{CeO}_{2-\mathrm{x}}(111)$ films using high resolution STM imaging, ${ }^{14,45}$ where they were formed via thermal desorption of oxygen in UHV rather than the photon induced effect demonstrated in this work. Introduction of $\mathrm{O}_{2}$ into the chamber up to a pressure of $\sim 5 \times 10^{-7}$ mbar at $300 \mathrm{~K}$ restored the LEED pattern of the ceria films on both $\mathrm{Pt}(111)$ and $\mathrm{Rh}(111)$ very rapidly (details provided in Figure S5) indicating that the defective $\mathrm{CeO}_{2-\mathrm{x}}$ surfaces produced by photon irradiation are extremely reactive.

As observed in the LEED/LEEM results shown in Figure 1, there is an O-(2×2) overlayer across the regions of the $\mathrm{Rh}(111)$ substrate uncovered by ceria, which can potentially play an important role in the reactivity of the inverse catalyst system. We note that at temperatures above $400 \mathrm{~K}$, this oxygen overlayer has very high mobility and the $(2 \times 2)$ structure disorders (see Figure S6). This temperature is similar to that required for the complete reoxidation of the ceria film, and suggests that the O$(2 \times 2)$ is involved in this process. In order to separate the roles of the gas phase and pre-adsorbed oxygen, the locally-reduced surface due to $\mathrm{x}$-ray exposure was subsequently annealed to $475 \mathrm{~K}$ under UHV conditions. The corresponding VB spectra and LEEM images are displayed in Figure 6. 


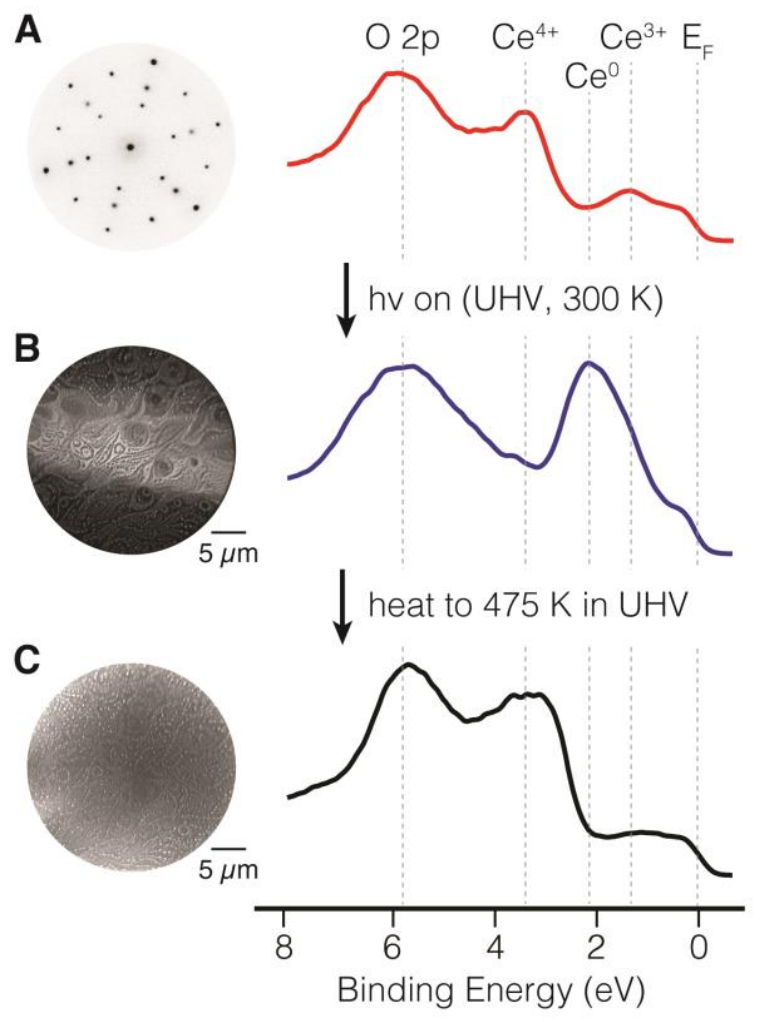

Figure 6. Reoxidation of ceria via oxygen spillover from $\mathrm{Rh}(111)-\mathrm{O}-(2 \times 2)$. (A) LEED $(30 \mathrm{eV})$ and Resonant VB XPS of the as-prepared film (B) LEEM (S.V. $=3.2 \mathrm{~V})$ and VB XPS after illumination with $120.8 \mathrm{eV}$ X-rays at $300 \mathrm{~K}$ in UHV (total exposure $8 \times 10^{19}$ ph.cm ${ }^{-2}$ (C) LEEM (S.V. $=3.2 \mathrm{~V}$ ) and VB XPS $(\mathrm{hv}=120.8 \mathrm{eV})$ after annealing to $475 \mathrm{~K}$ in UHV. Relatively small ceria islands are not resolved well in the large field of view.

At the start of the reaction sequence (Figure 6A) the ceria is almost fully oxidized, with only a small $\mathrm{Ce}^{3+}$ component, and a sharp LEED pattern as described in detail in Figure 1A. Note that the LEED pattern is a superposition of two diffraction patterns from laterally separated regions of $\mathrm{CeO}_{2}(111)$ and $\mathrm{O}-(2 \times 2) / \mathrm{Rh}(111)$. Upon exposure to the soft X-rays $(120.8 \mathrm{eV})$ the film is reduced (as observed in Figure 2) and a large shadow, corresponding to the beam footprint across the sample, can be observed in LEEM (Figure 6B). No changes to the $\mathrm{O}-(2 \times 2) / \mathrm{Rh}(111)$ layer were observed in LEED as a result of the irradiation. By simply heating the sample in UHV to $475 \mathrm{~K}$, the photon-induced reduction is completely reversed as seen in Figure 6C, where the resonant VB XPS shows a pure $\mathrm{Ce}^{4+}$ component. The contrast in LEEM due to the photon exposure is also completely removed. This complete reoxidation, in the absence of gas phase oxygen, leads us to propose that the $\mathrm{O}-(2 \times 2)$ overlayer on the substrate undergoes spillover onto the ceria islands at elevated temperature. In standard nomenclature this is referred to as reverse spillover. ${ }^{10}$ Some of the contrast change in the 
LEEM may be due to carbon accumulation occurring under the x-ray beam and subsequent oxidation by reaction with the O-(2×2) overlayer. C 1s XPEEM spectro-microscopy (see Figure S7) shows that the majority of the carbon is present in the gaps between the ceria, and not on the islands themselves. Lastly, we examined the capacity of the $\mathrm{O}-(2 \times 2)$ overlayer to act as a reservoir for the reoxidation, by reducing and reoxidizing the sample multiple times. We found that it is possible to only reoxidize two times before the $\mathrm{O}-(2 \times 2)$ overlayer became depleted (details in supporting information and Figure S8) In the typical Mars-van-Krevelen mechanism proposed for reactions such as $\mathrm{CO}$ oxidation over ceria-supported metal nanoparticles, the initial reaction of $\mathrm{CO}$ with oxygen from the ceria lattice generates an oxygen vacancy which is filled via reaction with gasphase $\mathrm{O}_{2}$. Our results identify an alternative process for this final step, i.e. that activated oxygen species can directly spillover from the $\mathrm{Rh}$ onto the ceria at 400-500 K, resulting in reoxidation of the oxide.

\section{CONCLUSIONS}

Well-ordered, ultrathin islands of $\mathrm{CeO}_{2}(111)$ supported on $\mathrm{Rh}(111)$ have been prepared as a model inverse catalyst system in order to probe the interaction between the reducible oxide and its metal support. Using high-resolution LEEM and XPEEM imaging and spectroscopy we have characterized the structure of the ceria and an $\mathrm{O}-(2 \times 2)$ overlayer on the $\mathrm{Rh}(111)$ substrate. Soft $\mathrm{x}-$ ray irradiation from an undulator beamline was used to reduce the ceria islands in situ, where spatially resolved, energy-filtered XPEEM was employed to observe that the reduction occurred at the edges and defects within the islands, highlighting the reactivity of the ceria/support interface in such an inverse catalyst. This photon-stimulated reduction induced a $(\sqrt{ } 7 \times \sqrt{ } 7) \mathrm{R} 19.1^{\circ}$ superstructure attributed to the $\mathrm{t}$-phase $\left(\mathrm{Ce}_{7} \mathrm{O}_{12}\right)(111)$ for thick ceria films on $\mathrm{Pt}(111)$. The reduced ceria films on $\mathrm{Rh}$ could be largely reoxidized by exposure to moderate pressures of $\mathrm{O}_{2}$ at $300 \mathrm{~K}$, although mild heating was required to fully reverse the reduction. Combining LEED and resonant VB XPS 
demonstrated that the activated oxygen species in the $\mathrm{O}-(2 \times 2) / \mathrm{Rh}(111)$ were able to directly spillover onto the reduced ceria islands at elevated temperatures (>400 K) leading to reoxidation, even under UHV conditions. On the basis of this work, we anticipate that on real catalysts oxygen will be provided by reverse spillover from the metal nanoparticles in the reoxidation cycle. 


\section{EXPERIMENTAL METHODS}

Measurements were carried out using the Elmitec Spectroscopic Photoemission and Low-Energy Electron Microscope (SPELEEM) at the Nanospectroscopy beamline (1.2L) at the Elettra synchrotron (Trieste, Italy). The experiments in this paper have employed LEEM in both brightand dark-field imaging modes as well as energy-filtered soft x-ray XPEEM and microprobe-XPS yielding both structural and chemical information. ${ }^{46,47}$ The $\mathrm{x}$-ray beam is produced by the undulator beamline in the range from $30 \mathrm{eV}$ to $1000 \mathrm{eV}$. The monochromatized photon flux can be as high as $10^{13}$ photons/sec, incident on an area of about $25 \mu \mathrm{m}(\mathrm{HOR}) \times 3 \mu \mathrm{m}$ (VER). The footprint of the $\mathrm{x}-$ ray beam on the sample is elongated in the horizontal direction due to the $16^{\circ}$ grazing incidence.

The $\mathrm{Rh}(111)$ and $\mathrm{Pt}(111)$ single crystals (Surface Prep. Lab., NL) were prepared by repeated cycles of $\mathrm{Ar}^{+}$sputtering and annealing to $1100 \mathrm{~K}$ in UHV and $800 \mathrm{~K}$ in $1 \times 10^{-6} \mathrm{mbar} \mathrm{O}_{2}$, followed by a final flash up to $1500 \mathrm{~K}$ in UHV. This procedure yielded well-ordered surfaces according to LEED and LEEM with no contamination observed in either XPS or XAS. In particular the presence of fluorine was tested, which has been previously discussed in the literature ${ }^{48,49}$ and no evidence was found of any such contamination of either our ceria films or the source Ce metal. Epitaxial $\mathrm{CeO}_{2}$ x(111) films were prepared by depositing Ce (99.9\%, Alfa-Aesar) onto the metal surfaces at $300 \mathrm{~K}$ in UHV from an electron-beam evaporator (Focus EFM-3) at a deposition rate of $0.02 \mathrm{ML} \mathrm{min}^{-1}$. This was followed by an oxidation step of annealing up to $\sim 1150 \mathrm{~K}$ in $5 \times 10^{-7} \mathrm{mbar}_{2} \mathrm{O}_{2}$ over the course of tens of minutes. The evaporation rate of cerium was calibrated by monitoring the attenuation of the $\operatorname{Rh}(111)(1 \times 1)$ LEED pattern during deposition according to the known growth mode exhibited by $\mathrm{Ce}$ on $\mathrm{Rh}(111) .{ }^{50}$ Ceria coverages are given in monolayer equivalents (MLE), where one monolayer is defined as the complete coverage of the surface by a single $\mathrm{CeO}_{2}$ trilayer unit, which has a height of $0.31 \mathrm{~nm}$. Thicknesses are calculated using the surface fractional coverage as measured in LEEM and confirmed by monitoring the attenuation of the Rh $3 \mathrm{~d}$ XPS peaks in XPEEM (see supporting information Figure S1). Photon energies employed to record core 
level spectra were as follows; Ce 4d, Rh 3d, and C 1s: 450 eV. For the Ce 4f resonant spectroscopy, the photon energies used were: $115 \mathrm{eV}, 120.8 \mathrm{eV}$ and $122.5 \mathrm{eV}$, corresponding to off-resonance, onresonance Ce 4d-4f $\left(\mathrm{Ce}^{3+}\right)$, and on-resonance Ce $4 \mathrm{~d}-4 \mathrm{f}\left(\mathrm{Ce}^{4+}\right)$, respectively. ${ }^{51}$ Binding energies are referenced to the Fermi level of the $\mathrm{Rh}(111)$ substrate. The electron kinetic energy (K.E.) in the SPELEEM instrument is controlled by applying a potential to bias the sample, namely the start voltage (S.V.). The kinetic energy of the emitted/scattered electrons is given by: K.E. $=$ S.V. $-\Delta \varphi$, where $\Delta \varphi$ is the difference in workfunction between the sample and the instrument of the order of 1 $\mathrm{eV}$. In the following, in discussing the LEEM and LEED data, we will specify the S.V. without a precise determination of the actual electron kinetic energy.

\section{ACKNOWLEDGEMENTS}

This work was supported by the European Research Council Advanced Grant ENERGYSURF (GT), the EU COST Action CM1104, the Royal Society, and the EPSRC (UK).

\section{SUPPORTING INFORMATION}

Supporting information is provided describing the following:

1. Estimation of ceria film thickness with XPS

2. LEEM contrast after $\mathrm{x}$-ray exposure

3. Evolution of the ceria oxidation state during $\mathrm{x}$-ray illumination under oxidising conditions

4. LEED evidence of reoxidation via $\mathrm{O}_{2}$ exposure

5. Temperature dependence of ceria/Rh(111) LEED pattern

6. XPEEM/XPS analysis of carbon contamination

7. Resonant VB spectra of ceria reoxidation via oxygen spillover 


\section{REFERENCES}

(1) Trovarelli, A.; de Leitenburg, C.; Boaro, M.; Dolcetti, G. The Utilization of Ceria in Industrial Catalysis. Catal. Today 1999, 50, 353-367.

(2) Nishikawa, Y.; Yamaguchi, T.; Yoshiki, M.; Satake, H.; Fukushima, N. Interfacial Properties of Single-Crystalline $\mathrm{CeO}_{2}$ High-K Gate Dielectrics Directly Grown on $\mathrm{Si}(111)$. Appl. Phys. Lett. 2002,81, 4386-4388.

(3) Jasinski, P.; Suzuki, T.; Anderson, H.U. Nanocrystalline Undoped Ceria Oxygen Sensor. Sensors and Actuators B 2003, 95, 73-77.

(4) Steele, B. C. H. Fuel-Cell Technology: Running on Natural Gas Nature 1999, 400, 619621.

(5) Trovarelli, A. Catalysis by Ceria and Related Materials; Imperial College Press, 2002.

(6) Haruta, M. Catalysis - Gold Rush. Nature 2005, 437, 1098-1099.

(7) Ngyuen, T.-S.; Morfin, F.; Aouine, M.; Bosselet, F.; Rousset, J.-L.; Piccolo, L. Trends in the CO Oxidation and PROX Performances of the Platinum-group Metals Supported on Ceria Cat. Today 2015, 253, 106-114.

(8) Ševčíková, K.; Kolářová, T.; Skala, T.; Tsud, N.; Vaclavu, M.; Lykhach, Y.; Matolín, V.; Nehasil, V.Impact of $\mathrm{Rh}-\mathrm{CeO}_{\mathrm{x}}$ Interaction on $\mathrm{CO}$ Oxidation Mechanisms Appl. Surf. Sci. 2015, 332, 747-755.

(9) Wrobel, R.; Suchorski, Y.; Becker, S.; Weiss, H. Cerium Oxide Layers on the $\mathrm{Cu}(111)$ Surface: Substrate-Mediated Redox Properties. Surf. Sci. 2007, 602, 436-442.

(10) Conner, W.; Falconer, J. Spillover in Heterogeneous Catalysis. Chem. Rev. 1995, 95, 759788.

(11) Rodriguez, J. A.; Ma, S.; Liu, P.; Hrbek, J.; Evans, J.; Perez, M. Activity of CeOx and $\mathrm{TiO}_{\mathrm{x}}$ Nanoparticles Grown on Au (111) in the Water-Gas Shift Reaction. Science 2007, 318, 1757-1760.

(12) Lu, J.; Gao, H.-J.; Shaikhutdinov, S.; Freund, H.-J. Gold Supported on Well-Ordered Ceria Films: Nucleation, Growth and Morphology in CO Oxidation Reaction.Catal. Lett. 2007, 114, 8-16.

(13) Š́koda, M.; Cabala, M.; Matolínová, I.; Prince, K. C.; Skála, T.; Šutara, F.; Veltruská, K.; Matolín, V. Interaction of $\mathrm{Au}$ with $\mathrm{CeO}_{2}(111)$ : a Photoemission Study. J. Chem. Phys. 2009, 130, 034703.

(14) Grinter, D. C.; Ithnin, R.; Pang, C. L.; Thornton, G. Defect Structure of Ultrathin Ceria Films on Pt(111): Atomic Views From Scanning Tunnelling Microscopy. J. Phys. Chem. C. 2010, 114, 17036-17041.

(15) Wilson, E. L.; Chen, Q.; Brown, W.; Thornton, G. CO Adsorption on the Model Catalyst $\mathrm{Pd} / \mathrm{CeO}_{2-\mathrm{x}}(111) / \mathrm{Rh}(111)$. J. Phys. Chem. C. 2007, 111, 14215-14222.

(16) Grinter, D. C.; Muryn, C.; Santos, B.; Shaw, B.-J.; Menteş, T. O.; Locatelli, A.; Thornton, G. Spectromicroscopy of a Model Water-Gas Shift Catalyst: Gold Nanoparticles Supported on Ceria. J. Phys. Chem. C. 2014, 118, 19194-19204.

(17) Grinter, D. C.; Pang, C. L.; Muryn, C. A.; Maccherozzi, F.; Dhesi, S. S.; Thornton, G. Characterising Ultrathin Ceria Films at the Nanoscale: Combining Spectroscopy and Microscopy J. Electron Spectr. Relat. Phenom. 2014, 195, 13-17.

(18) Grinter, D. C.; Yim, C. M.; Pang, C. L.; Santos, B.; Mentes, T. O.; Locatelli, A.; Thornton, G. Oxidation State Imaging of Ceria Island Growth on $\operatorname{Re}(0001)$. J. Phys. Chem. C. 2013, $117,16509-16514$.

(19) Flege, J. I.; Kaemena, B.; Senanayake, S. D.; Höcker, J.; Sadowski, J. T.; Falta, J. Growth Mode and Oxidation State Analysis of Individual Cerium Oxide Islands on $\mathrm{Ru}(0001)$ Ultramicroscopy 2013, 130, 87-93.

(20) Kaemena, B.; Senanayake, S. D.; Meyer, A.; Sadowski, J. T.; Falta, J.; Flege, J. I. Growth and Morphology of Ceria on Ruthenium (0001). J. Phys. Chem. C. 2013, 117, 221-232. 
(21) Flege, J.-I.; Kaemena, B.; Meyer, A.; Falta, J.; Senanayake, S. D.; Sadowski, J. T.; Eithiraj, R. D.; Krasovskii, E. E. Origin of Chemical Contrast in Low-Energy Electron Reflectivity of Correlated Multivalent Oxides: the Case of Ceria. Phys. Rev. B. 2013, 88, 235428.

(22) Skala, T.; Tsud, N.; Orti, M. Á. N.; Mentes, T. O.; Locatelli, A.; Prince, K. C.; Matolín, V. In Situ Growth of Epitaxial Cerium Tungstate (100) Thin Films. Phys. Chem. Chem. Phys. 2011, 13, 7083-7089.

(23) Senanayake, S. D.; Sadowski, J. T.; Evans, J.; Kundu, S.; Agnoli, S.; Yang, F.; Stacchiola, D.; Flege, J. I.; Hrbek, J.; Rodriguez, J. A. Nanopattering in $\mathrm{CeO}_{x} / \mathrm{Cu}(111)$ : a New Type of Surface Reconstruction and Enhancement of Catalytic Activity. J. Phys. Chem. Lett. 2012, 3, 839-843.

(24) Wang, J.; Morin, C.; Li, L.; Hitchcock, A. P.; Scholl, A.; Doran, A. Radiation Damage in Soft X-Ray Microscopy. J. Electron Spectr. Relat. Phenom. 2009, 170, 25-36.

(25) Günther, S.; Kaulich, B.; Gregoratti, L.; Kiskinova, M. Photoelectron Microscopy and Applications in Surface and Materials Science. Progr. Surf. Sci. 2002, 70, 187-260.

(26) Gregoratti, L.; Mentes, T. O.; Locatelli, A.; Kiskinova, M. Beam-Induced Effects in Soft X-Ray Photoelectron Emission Microscopy Experiments. J. Electron Spectr. Relat. Phenom. 2009, 170, 13-18.

(27) Pang, C. L.; Thornton, G. Photon-, Electron-, and Scanning Tunneling Microscopy-Induced Defects on Oxide Surfaces. In Defects at Oxide Surfaces; Springer Series in Surface Sciences 2015, 58, 429-451.

(28) Paparazzo, E.; Ingo, G. M. On the X-Ray Induced Chemical Reduction of $\mathrm{CeO}_{2}$ as Seen with X-Ray Photoemission Spectroscopy. J. Electron Spectr. Relat. Phenom. 1998, 95, 301-304.

(29) Paparazzo, E.; Ingo, G. M.; Zacchetti, N. X-Ray Induced Reduction Effects at $\mathrm{CeO}_{2}$ Surfaces: an X-Ray Photoelectron Spectroscopy Study. J. Vac. Sci. Tech. A 1991, 9, 14161420.

(30) Locatelli, A.; Pabisiak, T.; Pavlovska, A.; Mentes, T. O.; Aballe, L.; Kiejna, A.; Bauer, E. One-Dimensional Au on $\mathrm{TiO}_{2}$. J. Phys.: Condens. Matter 2007, 19, 082202.

(31) Guimond, S.; Sturm, J. M.; Göbke, D.; Romanyshyn, Y.; Naschitzki, M.; Kuhlenbeck, H.; Freund, H.-J. Well-Ordered $\mathrm{V}_{2} \mathrm{O}_{5}(001)$ Thin Films on $\mathrm{Au}(111)$ : Growth and Thermal Stability. J. Phys. Chem. C. 2008, 112, 11835-11846.

(32) Ercolani, D.; Lazzarino, M.; Mori, G.; Ressel, B.; Sorba, L.; Locatelli, A.; Cherifi, S.; Ballestrazzi, A.; Heun, S. GaAs Oxide Desorption Under Extreme Ultraviolet Photon Flux. Adv. Funct. Mater. 2005, 15, 587-592.

(33) Mori, G.; Lazzarino, M.; Ercolani, D.; Biasiol, G.; Locatelli, A.; Sorba, L.; Heun, S. X-Ray Induced Variation of the Chemistry of GaAs/AlAs Oxide Nanostructures. Nucl. Instr. Meth. Phys. Res. B 2006, 246, 39-44.

(34) Zakharov, A.A.; Johansson, U.; Leandersson, M.; Nylen, H.; Qvarford, M.; Lindau, I.; Nyholm, R. Metal-Dielectric Transition in $\mathrm{Ba}_{0.6} \mathrm{~K}_{0.4} \mathrm{BiO}_{3-y}$ Single Crystals Studied by Scanning Photoelectron Microscopy Phys. Rev. B 1997, 6, R5755-R5758.

(35) Günther, S.; Kolmakov, A.; Kovac, J.; Kiskinova, M. Artefact Formation in Scanning Photoelectron Emission Microscopy. Ultramicroscopy 1998, 75, 35-51.

(36) Cazaux, J. A Physical Approach to the Radiation Damage Mechanisms Induced by X-Rays in X-Ray Microscopy and Related Techniques. J. Microscopy 1997, 188, 106-124.

Knotek, M. L. Stimulated Desorption. Rep. Prog. Phys. 1999, 47, 1499-1561.

Knotek, M.; Feibelman, P. Ion Desorption By Core-Hole Auger Decay. Phys. Rev. Lett. 1978, 40, 964-967.

Marchini, S.; Sachs, C.; Wintterlin, J. STM Investigation of the $(2 \times 2) \mathrm{O}$ and $(2 \times 1) \mathrm{O}$ Structures on Rh(111). Surf. Sci. 2005,592, 58-64.

Matolin, V.; Matolínová, I.; Sedláček, L.; Prince, K. C.; Skála, T. A Resonant Photoemission Applied to Cerium Oxide Based Nanocrystals. Nanotech. 2009, 20, 215706. Škoda, M.; Libra, J.; Šutara, F.; Tsud, N.; Skála, T.; Sedláček, L.; Cháb, V.; Prince, K. C.; 
Matolin, V. A Resonant Photoemission Study of the Ce and Ce-Oxide/Pd(111) Interfaces. Surf. Sci. 2007, 601, 4958-4965.

(42) Yeh, J. J.; Lindau, I. Atomic Subshell Photoionization Cross Sections and Asymmetry Parameters: $1 \mathrm{Z}$ 103. Atomic data and nuclear data tables 1985, 32, 1-155.

(43) Wilkens, H.; Schuckmann, O.; Oelke, R.; Gevers, S.; Schaefer, A.; Baumer, M.; Zoellner, M. H.; Schroeder, T.; Wollschläger, J. Stabilization of the Ceria I-Phase $\left(\mathrm{Ce}_{7} \mathrm{O}_{12}\right)$ Surface on $\mathrm{Si}(111)$. App. Phys. Lett. 2013, 102, 111602.

(44) Höcker, J.; Mentes, T. O.; Sala, A.; Locatelli, A.; Schmidt, T.; Falta, J.; Senanayake, S. D.; Flege, J.-I. Unraveling the Dynamic Nanoscale Reducibility $\left(\mathrm{Ce} 4+\rightarrow \mathrm{Ce} 3+\right.$ ) of $\mathrm{CeO}_{\mathrm{X}}-\mathrm{Ru}$ in Hydrogen Activation. Adv. Mater. Interfaces 2015, 1500314

(45) Castellarin-Cudia, C.; Surnev, S.; Schneider, G.; Podlucky, R.; Ramsey, M.; Netzer, F. P. Strain-Induced Formation of Arrays of Catalytically Active Sites at the Metal-Oxide Interface. Surf. Sci. 2004, 554, L120-L126.

(46) Schmidt, T.; Heun, S.; Slezak, J.; Diaz, J.; Prince, K. C.; Lilienkamp, G.; Bauer, E. SPELEEM: Combining LEEM and Spectroscopic Imaging. Surf. Rev. Lett. 1998, 5, $1287-$ 1296.

(47) Locatelli, A.; Aballe, L.; Mentes, T. O.; Kiskinova, M.; Bauer, E. Photoemission Electron Microscopy with Chemical Sensitivity: SPELEEM Methods and Applications. Surf. Interface Anal. 2006, 38, 1554-1557.

(48) Pieper, H. H.; Derks, C.; Zoellner, M. H.; Olbrich, R.; Tröger, L.; Schroeder, T.; Neumann, M.; Reichling, M. Morphology and Nanostructure of $\mathrm{CeO}_{2}(111)$ Surfaces of Single Crystals and Si(111) Supported Ceria Films. Phys. Chem. Chem. Phys. 2012, 14, 15361.

(49) Kullgren, J.; Wolf, M. J.; Castleton, C. W. M.; Mitev, P.; Briels, W. J.; Hermansson, K. Oxygen Vacancies Versus Fluorine at $\mathrm{CeO}_{2}(111)$ : a Case of Mistaken Identity? Phys. Rev. Lett. 2014, 112, 156102.

(50) Napetschnig, E.; Schmid, M.; Varga, P. Growth of Ce on Rh (111). Surf. Sci. 2004, 556, 110.

(51) Matharu, J.; Cabailh, G.; Lindsay, R.; Pang, C. L.; Grinter, D. C.; Skála, T.; Thornton, G. Reduction of Thin-Film Ceria on Pt(111) by Supported Pd Nanoparticles Probed with Resonant Photoemission. Surf. Sci. 2011, 605, 1062-1066. 
Table of Contents Graphic

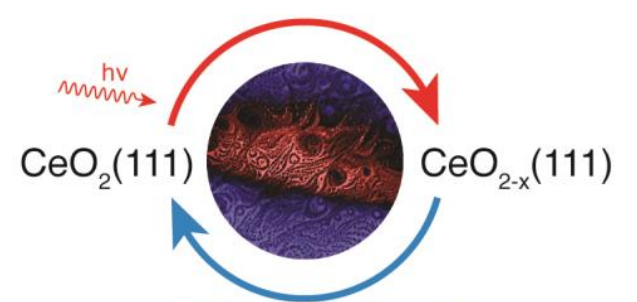

$\mathrm{Rh}(111)-\mathrm{O}-(2 \times 2)$ 